\title{
International Treaty Ratification and Leader Turnover
}

\author{
TOBIAS BÖHMELT \\ University of Essex and ETH Zürich
}

\begin{abstract}
Political leaders are ultimately responsible for their country's foreign policy, but our understanding of how executive turnover affects the likelihood of international treaty ratification remains limited. For contributing to this debate, I define leader change as the replacement of the executive leader by a new one who relies on different social groups for support. Focusing then on those cases where new leaders can assume office only from predecessors who plausibly supported treaty ratification, I expect that - in light of the predecessor's support for an agreement and the change in the domestic support base - leadership turnover makes ratification less likely. The empirical implication is tested with quantitative methods using data on multilateral treaties of the post-Cold War era. The main findings and a series of additional analyses provide strong and robust evidence for the theoretical argument. This research sheds new light on the determinants of multilateral cooperation as well as the role of government leaders in international affairs and foreign-policy decision-making.
\end{abstract}

Keywords: international agreements; leadership turnover; multilateralism; ratification; treaties

Supplemental material, the data set, and the replication files can be obtained from the author on request. I thank Gabriele Spilker, Yonatan Lupu, three anonymous reviewers, and the journal's editor-in-chief, Cameron G. Thies, for useful comments on an earlier draft. 
Many contemporary political issues are of a transnational nature and cannot be addressed by states solely at the domestic level or unilaterally. Transboundary air pollution, interstate trade, or international security concerns are just a few of those matters that require several nations' coordinated efforts at the international level in order to be regulated effectively. Arguably, the most prominent - and perhaps even necessary - instruments for doing so are international agreements, which are commonly defined as formal treaties between two or more countries that outline rules, regulations, and changes in state behavior for dealing with an international issue. Governments can commit to these treaties, join them, and participate in them usually by ratification or accession (see, e.g., Martin 1993; Schneider and Urpelainen 2013; Wangler et al. 2013; Lupu 2016).

This article seeks to shed light, theoretically and empirically, on how a change in the executive political leadership of a country shapes in turn the chances of ratifying an international treaty. To this end, I focus on what is arguably one of the most important influences in foreign-policy decision making: leaders are often the crucial actors in negotiating international agreements, they are the political actors that either ratify treaties themselves or submit an agreement to domesticlevel legislative bodies for confirmation after their signature, and they are ultimately responsible for their states' foreign policies. ${ }^{1}$ There is plenty of anecdotal evidence pointing toward the relevance of executive leader turnover in the context of ratification. Consider, for example, the US non-ratification of the Kyoto Protocol after George W. Bush replaced Bill Clinton as president of the United States (who, in fact, signed this agreement in 1997). ${ }^{2}$ Likewise, Donald J. Trump quickly withdrew US support for the Trans-Pacific Partnership (TTP) after assuming

\footnotetext{
${ }^{1}$ For a general overview of the importance of leaders, see, e.g., Bueno de Mesquita et al. (2003), Chiozza and Goemans (2004), McGillivray and Smith (2004, 2008), Goemans et al. (2009), Stanley (2009), Stanley and Sawyer (2009), Debs and Goemans (2010), Croco (2011), Bang et al. (2012), or Wolford (2012).

${ }^{2}$ Leaders are not the only actors in a political system affecting the process of treaty ratification. Many countries require parliamentary (legislative) approval for the ratification of an international agreement, making legislative bodies effectively a veto player (e.g., Mansfield et al. 2007, 2008; Lupu 2015). While I focus on the role of leaders in the following, I return to the influence of legislative bodies in the research design.
} 
office, while the Obama administration was strongly in favor of implementing this agreement. The non-ratification of multilateral cooperative efforts, particularly by key actors such as the US, usually has "major ramifications" (Bang et al. 2012: 756): it can significantly lower the effectiveness of international treaties or hamper future negotiations to come.

The following study contributes to this debate by systematically analyzing the relationship between leadership turnover and international treaty ratification. Wolford (2012: 519) states that "most state-centric research assumes that international agreements are robust to changes in leadership." While he refers to continued respect for a previously ratified international obligation, policymakers, public institutions, and scholars do not know whether Wolford's assessment applies (or not) in another context, i.e., continued support for an un-ratified but signed treaty, as well. In one of the first steps toward furthering our knowledge on how leader change affects a country's likelihood to ratify an international agreement, I focus on the replacement of the executive leader by a new one who relies on different social groups for support. This treatment is theoretically important and based on recently compiled data on leadership changes that involve the replacement of a leader's support base, i.e., source of leader support (SOLS) changes (Mattes et al. 2015, 2016).

The theory thus concentrates on the change in the ideological support base associated with a leadership turnover, and it does so in light of predecessors who were arguably supportive of ratifying an agreement. The latter is captured by the predecessor's signature of an agreement: signature largely is a "symbolic" act (Schneider and Urpelainen 2013: 14), and the consent of a state to be bound by a treaty is normally expressed by ratification as agreements usually emphasize that signatures are subject to that legal act (Art. 14 in the Vienna Convention on the Law of Treaties). However, signature does constitute a strong signal of a country's general willingness to fully join and be bound by an agreement in the future (see Baccini and Urpelainen 
2014; Hugh-Jones et al. 2016). I ultimately contend that leadership turnover should make ratification less likely given (1) the predecessor's support for an agreement and (2) the change in the domestic support base. Empirically, I employ logistic regression models on data of multilateral treaties that have been concluded in the post-Cold War era (Elsig et al. 2011; Milewicz and Elsig 2014), which I combine with own, recently compiled data on state signatures. The core results and several additional analyses that comprise a different estimator, different samples, or different approaches to calculate the standard errors robustly show that leadership turnover decreases the chances of treaty ratification.

The article crucially informs our understanding of the determinants behind countries' participation in international treaties as well as of the role of government leaders in foreignpolicy decision-making. My core finding is that leader turnovers significantly and substantially influence the likelihood of states participating in multilateral agreements. This result contributes to the vast literature on the determinants behind treaty ratification that, thus far, focused more on institutional or structural factors as explanations. With respect to the literature on leadership turnover, I make one central contribution. While there is anecdotal evidence that executive leadership change shapes the likelihood of agreement ratification, my study is the first to provide systematic evidence. While many scholars have sought to understand how leader turnover affects foreign policy more generally, including the continuation of support of an existing multilateral cooperation framework, few explore how the initial ratification decision is influenced. Particularly in light of this point, and assuming that those factors leading to a state's initial ratification decision also influence compliance with and the implementation of an agreement afterwards, the implications of my study go well beyond ratification as such. I conclude by discussing this research's significance for future scholarly work and policymakers. 


\section{The Impact of Leadership Turnover on Treaty Ratification: Theory}

Leaders are the focal point of interest in several fields of international relations or comparative politics (Goemans et al. 2009: 270f). For example, the impact of leaders and leader turnover features prominently in, among other fields, the study of international conflict (e.g., Chiozza and Choi 2003; Schultz 2005; Croco 2011; Quiroz Flores 2012; Wolford 2007, 2012), military coalitions and alliances (e.g., Leeds 2003; Stanley 2009; Stanley and Sawyer 2009; Pilster et al. 2015; Wolford and Hencken Ritter 2016), voting behavior in the United Nations and foreign policy decision-making in general (e.g., Levy 1994; Bueno de Mesquita et al. 2003; Mattes et al. 2015; Smith 2016), or trade relationships (e.g., McGillivray and Smith 2004, 2008; Hollyer and Rosendorff 2012; Bobick and Smith 2013). I concentrate on the impact of executive leadership change and, in more detail, only those leader turnovers that are accompanied by a change in the domestic social support base (Mattes et al. 2015, 2016). This treatment ensures that a change in the executive leadership always goes with a change in political ideology (at least to some extent). In addition, the theory also requires that all cases (those with and without a leadership turnover as defined above) are tied to a preceding government (before a potential leadership change may have occurred) having signaled that it would support ratification of an international treaty. ${ }^{3}$ Following Baccini and Urpelainen (2014) or Hugh-Jones et al. (2016), I use a government's signature of a treaty as a strong signal for that it intends to be bound by that agreement subject to ratification that then commits the government "more strongly" in a legally-binding way.

I argue that a new political leader will be significantly less likely to ratify an international agreement in light of the predecessor's support for an agreement and the change in the domestic support base. The underlying mechanism for this argument focuses on entrapment and leaders'

\footnotetext{
${ }^{3}$ Note here that this ensures that leader turnover can only occur after a treaty has been opened for ratification, and after a predecessor government (if any) signalled its willingness to ratify a treaty. In other words, the incoming leader has not been involved in negotiating or drafting an agreement.
} 
preferences and beliefs. I develop this mechanism in four steps and it is based on the assumption that leaders are office seeking. Therefore, I assume that they at least try not to displease their domestic audiences with foreign policy decisions and, hence, also when considering the ratification of international treaties (see Downs 1957: 28; Schelling 1960; Putnam 1988: 434; Vertzberger 1998: 214; Bueno de Mesquita et al. 2003). ${ }^{4}$ This assumption applies to nondemocratic states as well (see, e.g., Goemans 2000; Croco 2011). However, a reasonable objection to this may be in my context that the content of agreements and the issues they address may not be that salient to the domestic audience, and it may well be suggested that the majority of the electorate is indifferent to these policies. There are three arguments against this.

First, international treaties are, in fact, frequently more salient to domestic audiences than conventional wisdom may suggest. The domestic-level debates in several European countries in the context of the Comprehensive Economic and Trade Agreement (CETA) or Transatlantic Trade and Investment Partnership (TTIP) illustrate this. Regarding TTIP, for instance, 97 percent of about 150,000 respondents in a European Commission survey on TTIP had largely negative views. ${ }^{5}$ Numerous protests in Europe against TTIP further underline that the (at least the European) public actually had (and still has) very strong views on this multilateral trade agreement. Second, Cazals and Sauquet (2015: 266) examine international environmental treaties and claim that "leaders act strategically even when it relates to secondary policy issues." Hence, leaders are likely to take into account their domestic constituents for the ratification decisions considered here, too; and even the dissatisfaction of a small domestic group may have an impact. Third, derived from the previous two arguments, following Mattes et al. (2015: 283), states'

\footnotetext{
${ }^{4}$ As Putnam (1988: 434) emphasizes, "any leader who fails [in international negotiations] to satisfy his fellow players at the domestic table risks being evicted from his seat." And in the words of Wangler et al. (2013: 391), "a government's proposal at international negotiations should be acceptable to its domestic constituents because this, in the end, will help to win elections."

5 See http://europa.eu/rapid/press-release_IP-14-292_en.htm.
} 
treaty-ratification behavior represents "an indirect reflection of the foreign policy position of a state," which usually is important to the domestic audience. Put differently, a country's decision to participate or not in an international agreement "is a latent indicator of its foreign policy orientation $[\ldots]$; it is a record of how the state wants to be seen by others, the international norms it finds acceptable, and the positions it is willing to take publicly on a wide variety of issues" (Mattes et al. 2015: 283). Domestic audiences do care about this, and they take into account the costs (and benefits) an international commitment may impose on them.

In light of this, my argument then focuses on situations in which a new leader replaces one who has signaled support for ratifying an agreement by her signature (Baccini and Urpelainen 2014; Hugh-Jones et al. 2016). As indicated, leader transitions refer to those cases where the new leader relies on different social groups for support, i.e., SOLS changes (Mattes et al. 2015, 2016). I develop the argument and its underlying mechanism in four steps. First, among other factors, domestic interest groups, political factions, and the general domestic public are likely to condition their support of a leader on the country's foreign policy - and the participation or nonparticipation in a specific international treaty is a direct reflection of that (Schelling 1960; Putnam 1988; McGillivray and Smith 2008; Cazals and Sauquet 2015; Mattes et al. 2015). Second, political leaders who are in favor of joining an agreement - potentially because this satisfies their domestic audience, political factions, and interest groups - signal their willingness to do so via signing it (see also Baccini and Urpelainen 2014; Hugh-Jones et al. 2016). ${ }^{6}$

In turn, third, though, leaders are committed to a treaty by their own constituencies at the domestic level - they are "entrapped” (see also Stanley 2009; Stanley and Sawyer 2009: 657;

\footnotetext{
${ }^{6}$ Clearly, not all states that have not signed a treaty do oppose it. Frequently, governments immediately ratify a treaty and this makes signature unnecessary. However, the empirical analysis requires a clear and observable signal of support for an international agreement before ratification, and only signature can provide this. In light of this discussion, the results I obtain are, in fact, conservative estimates as it is likely that I omit a series of cases where leaders have not publicly expressed their support for an agreement before a leadership turnover.
} 
Croco 2011). Indeed, leaders' original support for an agreement was presumably based on what they believe their domestic constituency wants. In case a leader's foreign policy would go against these groups' interests, they may sanction her by withdrawing support. Industrial sectors interested in certain trade or economic policies, bureaucratic groups implementing international security or environmental treaties, or members of the winning coalition are all potential veto players in this context (Vertzberger 1998: 105ff). In addition, leaders themselves might believe that it is "the right thing" to support joining a treaty. However, beliefs are stable and unlikely to change over the course of office of one political leader (Saunders 2009: 131f): if the leader in office supports the ratification of an agreement, she will probably not change her beliefs during her tenure.

Fourth, this implies that only a new leader with a different political orientation, stemming from a different domestic social support base, is likely to change a state's foreign policy, including the way the ratification of an international agreement is seen. It is then only leader turnover that is likely able to move out of "entrapment." New leaders with a different political orientation are likely to have dissimilar beliefs, ideologies, and perceptions regarding foreign policy - and the commitment to multilateral efforts at the international level (Walker 1983: 181ff; Wolford 2007: 774; Saunders 2009: 129ff). This is because they represent new constituencies with interests that may differ from those of the previous leaders and her support base (McGillivray and Stam 2004: 160ff; Croco 2011). As Wolford (2012: 517) emphasizes, "leadership turnover may produce significant foreign policy changes when leaders differ from their predecessors in their preferences. A difference in those beliefs is likely to be only given if the prior and the new leader clearly differ in their political orientation." These varying preferences or beliefs result in contrasting evaluations of the benefits a state can derive from 
ratifying an international agreement. Ultimately, the likelihood of ratification decreases with leader turnover if the predecessor supported a treaty and the new one has a different support base.

I thus conclude that new leaders with new constituencies, which brought them into power and that have interests differing from those of the previous leader, are more likely to depart from their predecessors' ratification intention. To be clear, international agreements do entail benefits and probably even so for incoming leaders, but their perceptions and rationale might tell them to pursue decisions that differ from their predecessors, and they then do not pursue ratification: considering ratifying a treaty that the predecessor has deliberately decided to commit to via their signature is unlikely to consolidate a new leader's power (see also Cazals and Sauquet 2015: 266). ${ }^{7}$ Eventually, the mechanism I outlined points to the following empirical expectation:

Leadership Turnover Hypothesis: Political leadership turnover with a change in the domestic support base is associated with a lower likelihood of international agreement ratification if the predecessor supported an agreement.

\section{Research Design}

Data, Dependent Variable, and Methodology

Figure 1 graphically depicts the time frame of events underlying my theoretical argument. This graph also highlights two important points. First, I analyze a sample that comprises only those treaty-country pairs (which constitute my unit of analysis) that actually saw a (preceding) government signing that agreement. If I would consider also treaty-country pairs that did not see a signature before ratification, I would lack a credible signal on whether a government is willing

\footnotetext{
${ }^{7}$ A possible objection to this argument may be that leadership tenures in the data I use are too long: eventually, power will be secured and more "risky" policies become more likely. Note, however, that the average duration of a treaty-country pair in my data is 4.34 years only. I address this concern further in the Supplementary Materials with a sample that omits longer treaty-country spells and a duration model capturing the time elapsed until ratification. Also note the estimations in Table 3 below.
} 
to eventually fully join an agreement. ${ }^{8}$ Second, the critical points in time in my analysis do not overlap, i.e., signature has to precede leadership change (if any), which in turn has to occur before ratification (if any).



Figure 1. Time Frame of Focal Events

Against this background, the empirical analysis focuses on SOLS changes (Mattes et al. 2015, 2016) and a clear signal of support for a treaty by a preceding government for examining how leadership turnover is related to the ratification of treaties. As a general data framework, I employ one of the most recent data sets on international cooperation efforts by Elsig et al. (2011; see also Milewicz and Elsig 2014). These scholars compiled information on multilateral treaties that have been concluded in the post-Cold War period and (1) are universal to the extent that all recognized states can potentially ratify them, ${ }^{9}$ (2) address global concerns, and (3) depart from previous practice, i.e., agreements do not merely mirror pre-existing commitments, but depart from existing state policies. Due to the last coding criterion, it is ensured that states have to change their current behavior at least to some extent. Hence, adjustments are necessary and, therefore,

\footnotetext{
${ }^{8}$ This is solely an empirical point and does not imply that the scope conditions of the theory are limited. The theory also applies to treaties that come into force, e.g., simply based on signature. A leadership change before this legal act may well influence, in fact, whether a state will eventually join that agreement via signing it. That said, relying on the sequence of signature and then (potentially) ratification ensures that I can observe a credible signal on whether a state intends to eventually support and join a treaty.

${ }^{9}$ Ratification is required for all treaties in this data set to come into force - signature alone is insufficient.
} 
ratification of any treaty regardless of the issue area in the data set is associated at least initially with costs (see also Cazals and Sauquet 2015: 267). Also, these agreements can then potentially affect the status quo and produce relevant outcomes in their diverse policy areas substantially which is what the domestic audience will have anticipated and noticed, and may have taken into account in their support for the leader (see also Mattes et al. 2015). In fact, most of the agreements in the sample address highly salient issue areas, e.g., the Kyoto Protocol (for environment), several World Trade Organization treaties (trade), the Chemical Weapons Convention (security and crime), or the Hague Convention of International Protection of Adults (human rights).

The data by Elsig et al. (2011; see also Milewicz and Elsig 2014) only provide information on the agreement's name and the year of ratification. As I also require information on whether a (predecessor) government potentially supported the ratification of a treaty, I compiled the data on state signatories (if any) and the year of their signature myself. Primarily, I relied on the United Nations Treaty Collection database ${ }^{10}$ for this, but also used primary sources such as agreement websites. I then combined the information on signature with the ratification data by Elsig et al. (2011; see also Milewicz and Elsig 2014) in order to create a sample of treaty-country pairs in the post-Cold War period that have seen signature before a leadership change or ratification (if any). That is, treaty-country combinations where the agreement has not been signed and those where signature and leadership change overlap, are omitted from the analysis. The data by Elsig et al. (2011; see also Milewicz and Elsig 2014) originally comprise 76 international agreements, and I was able to collect signature data for 53 of them. A list of treaties in my data is given in the Supplementary Materials. ${ }^{11}$

\footnotetext{
10 See https://treaties.un.org/.

${ }^{11}$ Unfortunately, I lack reliable data on treaties' degree of legalization, which would allow me to analyze more effectively what kind of costs or benefits are associated with each agreement for the countries in my sample. Since
} 
Many studies on ratification use the treaty-country year as the unit of analysis and model whether a treaty-country dyad "fails" in a given year, i.e., a treaty has been ratified (e.g., Bernauer et al. 2010, 2013; Elsig et al. 2011; Milewicz and Elsig 2014). This approach seems not necessarily appropriate in my context due to two reasons. First, the treaty-country year seems only suitable when potential temporal lags can be easily identified, i.e., if there is an immediate or a one-year lagged impact of an explanatory variable on ratification. It seems plausible that such an effect is given for, e.g., economic factors or regime type. That said, it is likely that the lag structure of an effect is more complex when focusing on leadership turnovers. For example, may a leadership turnover in $t$ only have an effect on ratification in $t+1$ ? Or may it also affect ratifications in the second, third, or fourth year after a new leader assumed office? Eventually, a higher degree of aggregation seems warranted for addressing potential concerns in this regard and in terms of endogeneity more generally. Second, using the treaty-country year as the unit of analysis induces an artificial increase of (or multiplication in) the number of observations. A large number of observations decreases the standard errors, making it more difficult not to find statistically significant results. However, such statistical significance may be entirely driven by the artificially large number of observations, and not by actually existing statistically significant relations between variables (see Cranmer et al. 2012). As Erikson et al. (2009) show, minor effects could achieve unrealistically low $p$-values under those circumstances. This discussion leads to the concern that multiplying treaty-country pairs by years could lead to "erroneous conclusions" and "bias statistical analysis by inflating the number of events we are trying to model" (Cranmer et al. 2012: 285).

To this end, I use the treaty-country as a unit of analysis, i.e., I aggregate a treaty-country pair over the years until ratification or the end of the observation period in my data (in case

all treaties constitute a "departure from previous practice," nevertheless, it is obvious that they are initially indeed costly (at least to some degree). 
ratification did not occur) and, therefore, create a "spell" for every pair of an international agreement and a state that can potentially ratify it. This approach not only addresses endogeneity concerns, such as simultaneity between treaty ratification and leader change (see also Quiroz Flores 2012), but also addresses problems associated with unclear temporal lag structures and it avoids artificially increasing the number of observations (see also Bernauer et al. 2010, 2013; Elsig et al. 2011). Considering this structure, most time-varying explanatory variables (described below) are set at starting values (i.e., values at the beginning of a treaty-country pair). Note, however, that my results are virtually unchanged when moving to a duration estimation framework (that then takes right-censoring into account) or using the treaty-country-year as the unit of analysis. Both analyses are summarized in the Supplementary Materials.

After aggregating the data from Elsig et al. (2011; see also Milewicz and Elsig 2014) to the treaty-country level, I obtain 2,670 spells. The combinations of a treaty with any country in the world that signed before a leadership turnover (if any) (treaty-country spell) enter the data set as soon as the focal treaty is open for ratification between 1990 and 2004; for each treaty-county pair, the year of ratification is coded or, if a state has not joined a treaty by the end of 2008 , it is coded that ratification has not occurred. Based on this information, I created a binary ratification variable that receives the value of 1 if the agreement in a treaty-country spell has been ratified by the end of 2008 or the value of 0 if no ratification occurred. Following Elsig et al. (2011; see also Milewicz and Elsig 2014), I treat different legal expressions of formally joining a treaty, e.g., accession or approval, as equivalent to ratification. Out of the 2,670 treaty-country spells in my data, about 81 percent of them saw ratification until 2008. This further underlines my claim that signature, in fact, is a very strong signal for a country's willingness to eventually join an agreement. That said, note that sufficient variation does exist for the outcome item. 
Because of the dichotomous nature of the dependent variable, I use logistic regression models. I cluster the standard errors at the country level to control for potential intra-group correlations. Similarly, as a country's earlier ratification of one agreement might affect the same state's current chances to join another one, I control for temporal autocorrelation with cubic polynomials on the time elapsed (in years) since the last ratification of another treaty (Carter and Signorino 2010). Finally, coefficients in logistic regression models do not allow for a direct interpretation and I thus present predicted probabilities of ratification for the values of my core explanatory variable: leadership turnover.

\section{Core Explanatory Variable: Leadership Turnover - SOLS Change}

My main independent variable pertains to political leadership change and, more specifically, turnovers that are accompanied by a change in the domestic support base. As a result, I only focus on those leader turnovers that are associated with a change in the "source of leader support" (SOLS) (Mattes et al. 2015, 2016). I use the Change in Source of Leader Support (CHISOLS) data compiled by Mattes et al. (2016). The CHISOLS data set codes SOLS changes based on the domestic support base of a leader, while the leadership transitions as such in the data are taken from the Archigos data (Goemans et al. 2009).

In democracies, SOLS changes usually "occur when the political party of the chief executive changes" (Mattes et al. 2016: 3); in non-democracies, SOLS changes are coded along the institutional setups of an autocratic regime and, to this end, only "transitions from one autocratic type to another" are coded as SOLS changes (Mattes et al. 2016: 4). For example, single-party regimes see a SOLS change when the party in power changes, monarchies experience such a leadership transition when the ruling dynasty ends, and military regimes or personalist dictators are not coded as SOLS changes when a single continuous military regime or dictator is in place. 
Predesignated successors, especially something that occurs in personalist dictatorships, are not coded as changes, but only "cases in which a new leader with his own clique comes to power" (Mattes et al. 2016: 4).

The detailed coding rules are available in Mattes et al. (2016). Based on the CHISOLS data set, I created a binary variable (SOLS Change) that receives a value of 1 if (1) exactly only one SOLS change has taken place and (2) that leadership turnover occurred after signature and before any ratification act. Hence, I omit treaty-country pairs with more than one SOLS change over the duration of a spell and I ignore years in which ratification (or signature) and SOLS change simultaneously occurred due to endogeneity concerns. In addition, using this coding procedure with the treaty-country unit of analysis ensures that every single treaty in my sample has been concluded and opened for ratification before the new leader assumes power. Hence, it is unlikely that incoming leaders have influenced the design and commitments of an international agreement - they have to make the ratification decision, though. Ultimately, I have information for all 2,670 treaty-country pairs in my sample and about 13 percent of them have indeed seen exactly one SOLS change before ratification occurred (or the end of the sample period, i.e., 2008).

\section{Control Variables}

I control for several items that capture alternative explanations for why states may ratify international treaties and/or variables that could affect the chances of leader turnover in a country. For these additional variables, I follow the previous literature, which highlights that there are primarily three clusters of determinants that may influence countries' chances of ratifying international treaties (see also Schneider and Urpelainen 2013; Wangler et al. 2013; Yamagata et al. 2013). First, there are international-level variables such as trade openness (e.g., Bernauer et al. 2010, 2013; Elsig et al. 2011; Milewicz and Elsig 2014; Bernauer et al. 2010; Spilker 2013; 
Yamagata et al. 2013). Second, there are domestic-level characteristics such as political regime type (e.g., Mansfield et al. 2002; Neumayer 2002a,b; see also Fredriksson and Gaston 2000; von Stein 2008; Bernauer et al. 2010; Elsig et al. 2011; Milewicz and Elsig 2014). Finally, there are spatial dependencies, i.e., a state's commitment to international agreements may be affected by other nations' actions in this regard (e.g., Fredriksson and Gaston 2000; Neumayer 2002a,b; Roberts et al. 2004; Fredriksson et al. 2007; von Stein 2008; Bernauer et al. 2010, 2013).

Against this background, first, I include data on a country's membership in IOs (IGO Membership), using the total number of intergovernmental organization of which a country is a member of (Pevehouse et al. 2004). Since my unit of analysis aggregates time over a treatycountry spell, the variable captures the membership count of a state in the first year of the corresponding treaty-country pair. Second, to measure a country's level of democracy, I use the combined polity 2 variable from the Polity IV project that ranges from -10 (full autocracy) to +10 (full democracy) (Marshall and Jaggers 2004). The sample is not biased against non-democracies, since about 40 percent of the treaty-country pairs receive a value of +5 or lower on the polity scale. As in the case of IGO Membership, the variable Democracy captures a state's polity score in the first year of its corresponding treaty-country pair entering the data.

Third, I calculated a variable counting the total number of states in the international system that ratified the treaty in question by the end of a treaty-country spell (Number of Countries Ratified). This approach essentially follows the logic of a spatial lag, although countries' links are not weighted by some sort of proximity measure (Franzese and Hays 2007). In addition, Elsig et al. (2011) and Milewicz and Elsig (2014) consider State Power, i.e., an item on a country's national material capabilities comprising information on (1) military expenditure, (2) military personnel, and (3) energy consumption. According to Elsig et al. (2011) and Milewicz and Elsig 
(2014), treaty ratifications should increase with capabilities. The variable is measured in the first year a state of a treaty-country pair is included in the sample.

Fifth, there is a country's trade openness, measured as the ratio of a state's sum of exports and imports to GDP (Trade Openness) in the first year of a treaty-country spell. This variable is based on the Penn World Tables (version 6.3). Moreover, leaders are more accountable, the more their fate depends on the selectorate, i.e., the set of people who have the ability to choose a country's leader, and the winning coalition, i.e., the portion of the selectorate that keeps a leader in power (Bueno de Mesquita et al. 2003). While some regime types may be generally more accountable than others, accountability matters particularly for leaders when citizens express their will on their performance via national elections (see Smith and Hayes 1997). This also applies at least to some extent to (partly) non-competitive elections that are frequently held in autocratic regimes (Gandhi and Przeworski 2006). In line with this reasoning, several studies show that leaders time their political decisions according to the electoral agenda (e.g., Nordhaus 1975; Brender and Drazen 2005; Shi and Svensson 2006). The ratification of international treaties may not be an exception here. The data on election dates are taken from Goemans's extension of the Archigos data (Goemans et al. 2009). I use a dummy variable indicating if a country-treaty pair has seen any election (1) or not (0). This operationalization captures the context of national elections, i.e., following Cazals and Sauquet (2016), I consider that leaders may take into account the domestic audience before elections as well (see also Chiozza and Choi 2003: 263; Smith and Hayes 1997). I combine information on presidential and parliamentary elections, i.e., national elections in general, as both types of elections are equally likely to matter for an executive leader's concerns over accountability and voters' potential punishment.

Countries with constitutions that ask for explicit legislative approval may be less likely to ratify international agreements, as the required consent of legislators constitutes another veto 
obstacle in the process of ratification. Eventually, additional, potentially divergent preferences lead to a policy stasis and a lower likelihood of ratification (see also Spilker and Koubi 2016). Legislative bodies thus play a major role for the ratification of an international agreement: for example, "both congressional chambers must agree to the required changes in US domestic law" (Bang et al. 2012: 756). Employing the data from Hathaway (2007), I constructed a variable on whether legislative approval is needed in any house of a state's legislature. The data are based on the constitutions of all countries in 2007. As constitutional provisions rarely change, if at all, I treat this item as time-invariant. The models below demonstrate as well, though, that my core result holds even when omitting this variable (and all others). About 78 percent of 2,611 treatycountry spells are characterized by the need for legislative approval of the executive's ratification decision.

Table 1. Descriptive Statistics

\begin{tabular}{|c|c|c|c|c|c|c|}
\hline & Obs. & Mean & Std. Dev. & Min. & Max. & VIF \\
\hline Ratification & 2,670 & 0.807 & 0.394 & 0 & 1 & \\
\hline SOLS Change & 2,670 & 0.132 & 0.339 & 0 & 1 & 1.14 \\
\hline Election & 2,670 & 0.657 & 0.475 & 0 & 1 & 1.18 \\
\hline Number Countries Ratified & 2,670 & 74.616 & 45.490 & 0 & 185 & 1.26 \\
\hline Democracy & 2,298 & 3.982 & 6.490 & -10 & 10 & 1.33 \\
\hline Security and Crime Treaty & 2,670 & 0.378 & 0.485 & 0 & 1 & 2.16 \\
\hline Environmental Treaty & 2,670 & 0.321 & 0.467 & 0 & 1 & 2.17 \\
\hline Trade Treaty & 2,670 & 0.145 & 0.352 & 0 & 1 & 1.73 \\
\hline Human Rights Treaty & 2,670 & 0.157 & 0.364 & 0 & 1 & Baseline \\
\hline State Power & 2,642 & 0.004 & 0.049 & -0.012 & 0.473 & 1.09 \\
\hline Trade Openness & 2,522 & 81.425 & 48.390 & 2.008 & 456.562 & 1.14 \\
\hline IGO Membership & 2,651 & 65.443 & 23.107 & 6 & 129 & 1.35 \\
\hline Legislative Approval & 2,611 & 0.780 & 0.414 & 0 & 1 & 1.04 \\
\hline
\end{tabular}

Note: Variables for temporal correction are omitted from the table. The Variance Inflation Factors have been calculated while leaving out the baseline category for the treaty issue areas. 
Finally, I use the treaties' underlying issue areas (human rights, environment, security, and trade) as control variables, which then capture the rationale that the salience and costs of treaties are likely to vary over issue area and, consequently, affect the cost-benefit analysis of governments. The data for these four controls, i.e., Human Rights Treaty, Security and Crime Treaty, Environmental Treaty, and Trade Treaty, are taken from Elsig et al. (2011) and Milewicz and Elsig (2014), and I use Human Rights Treaty as the reference agreement type (i.e., this variable is left out of the models as the baseline). Table 1 gives an overview of the descriptive statistics of all variables I discussed so far.

\section{Empirical Findings}

Table 2 summarizes the main models of my empirical analysis. The first model focuses on $S O L S$ Change as the only explanatory variable next to the temporal controls. Clarke $(2005,2009)$, for example, argues that control variables may increase the bias in model estimates, and not decrease it, under specific circumstances. Model 2 then drops the main independent variable and incorporates the control covariates only. Finally, Model 3 constitutes my core model as both the main explanatory item and the controls are jointly considered. For assessing the models' fit, I report logarithmic (pseudo) likelihoods, $\chi^{2}$ test statistics, and the Akaike Information Criterion (AIC), which is multiplied by the number of observations in each model. In general, the smaller the AIC, the better the model fit. As indicated above, I also report predicted probabilities of treaty ratification in Figure 2 for the different values of SOLS Change. And, finally, I analyze the predictive validity of the results by reporting the expected percent of correctly predicted cases as well as the predicted proportional reduction in error (Herron 2000) in Table 2. To assess the robustness of my results, I examine various alternative model specifications, which and their 
corresponding results are summarized in the Supplementary Materials. These robustness checks further support the findings discussed in the following.

First, Table 2 provides strong support for my theory. Regardless of the model specification, SOLS Change exerts a negative and highly significant impact on the likelihood of treaty ratification. My main explanatory variable also contributes to the model fit as demonstrated by the shift in the AIC across Models 2 and 3. In more substantive terms, Figure 2 shows the predicted probabilities of treaty ratification under two different scenarios: first, when SOLS Change receives the value of 1, i.e., there was exactly one replacement of a government leader by a new one who relies on different social groups for support before ratification occurred; and, secondly, when SOLS Change=0, i.e., when there was no leadership turnover before a treatycountry spell has seen ratification (if any). I calculated these substantive quantities of interest while holding all other variables constant at their median values along the lines of King et al. (2000). As the probabilities are simulated parameters, I present density plots that capture their distribution, and the horizontal bars at the bottom of Figure 2 signify the point estimates of the two scenarios' probabilities and their 90 percent confidence intervals.

When there was exactly one replacement of a government leader by a new one who relies on different social groups for support before ratification, the predicted probability of treaty ratification after that leadership turnover in a treaty-country spell is around 56 percent. Conversely, this probability increases by about 30 percentage points to 86 percent when there was no leadership turnover associated with a different support base, i.e., when changing SOLS Change to 0 . Note that the horizontal bars for the probability point estimates' confidence intervals do not overlap, which means that the difference between the two scenarios' predicted probabilities is statistically significant. 
Table 2. Leadership Turnover and Treaty Ratification - Logistic Regressions

\begin{tabular}{|c|c|c|c|}
\hline & Model 1 & Model 2 & Model 3 \\
\hline SOLS Change & $\begin{array}{l}-1.244 \\
(0.222)^{* * *}\end{array}$ & & $\begin{array}{l}-1.588 \\
(0.278)^{* * *}\end{array}$ \\
\hline Election & & $\begin{array}{l}-1.013 \\
(0.179)^{* * *}\end{array}$ & $\begin{array}{l}-0.701 \\
(0.190)^{* * *}\end{array}$ \\
\hline Number of Countries Ratified & & $\begin{array}{l}-0.000 \\
(0.002)\end{array}$ & $\begin{array}{c}0.001 \\
(0.002)\end{array}$ \\
\hline Democracy & & $\begin{array}{l}0.069 \\
(0.013)^{* * *}\end{array}$ & $\begin{array}{l}0.097 \\
(0.016) * * *\end{array}$ \\
\hline Security and Crime Treaty & & $\begin{array}{l}-0.122 \\
(0.157)\end{array}$ & $\begin{array}{l}-0.116 \\
(0.159)\end{array}$ \\
\hline Environmental Treaty & & $\begin{array}{l}1.416 \\
(0.217)^{* * *}\end{array}$ & $\begin{array}{l}1.442 \\
(0.228) * * *\end{array}$ \\
\hline Trade Treaty & & $\begin{array}{l}-0.767 \\
(0.182)^{* * *}\end{array}$ & $\begin{array}{l}-0.571 \\
(0.190) * * *\end{array}$ \\
\hline State Power & & $\begin{array}{l}-3.361 \\
(1.319)^{* *}\end{array}$ & $\begin{array}{l}-3.252 \\
(1.603) * *\end{array}$ \\
\hline Trade Openness & & $\begin{array}{l}-0.003 \\
(0.002)\end{array}$ & $\begin{array}{l}-0.004 \\
(0.002)^{* *}\end{array}$ \\
\hline IGO Membership & & $\begin{array}{l}-0.014 \\
(0.004)^{* * *}\end{array}$ & $\begin{array}{l}-0.017 \\
(0.005) * * *\end{array}$ \\
\hline Legislative Approval & & $\begin{array}{l}0.371 \\
(0.183)^{* *}\end{array}$ & $\begin{array}{l}0.334 \\
(0.194) *\end{array}$ \\
\hline Time Since Last Ratification & $\begin{array}{l}1.531 \\
(0.411)^{* * *}\end{array}$ & $\begin{array}{l}1.701 \\
(0.487)^{* * *}\end{array}$ & $\begin{array}{l}1.523 \\
(0.504) * * *\end{array}$ \\
\hline Time Since Last Ratification ${ }^{2}$ & $\begin{array}{l}-0.665 \\
(0.310)^{* *}\end{array}$ & $\begin{array}{l}-0.706 \\
(0.387)^{*}\end{array}$ & $\begin{array}{l}-0.597 \\
(0.399)\end{array}$ \\
\hline Time Since Last Ratification ${ }^{3}$ & $\begin{array}{c}0.045 \\
(0.048)\end{array}$ & $\begin{array}{c}0.041 \\
(0.060)\end{array}$ & $\begin{array}{c}0.025 \\
(0.063)\end{array}$ \\
\hline Constant & $\begin{array}{l}1.444 \\
(0.101)^{* *}\end{array}$ & $\begin{array}{l}2.670 \\
(0.468)^{* * *}\end{array}$ & $\begin{array}{l}2.794 \\
(0.524) * * *\end{array}$ \\
\hline Observations & 2,670 & 2,221 & 2,221 \\
\hline Log pseudolikelihood & $-1,220.77$ & -895.60 & -844.15 \\
\hline Wald $\chi^{2}$ & $71.18 * * *$ & $182.51 * * *$ & $184.80 * * *$ \\
\hline Expected Percent Correctly Predicted & 0.71 & 0.74 & 0.76 \\
\hline Expected Proportional Reduction in Error & 0.07 & 0.14 & 0.20 \\
\hline $\operatorname{AIC}(* N)$ & $2,451.55$ & $1,819.20$ & $1,718.29$ \\
\hline
\end{tabular}

Note: Robust standard errors clustered on country in parentheses.

* significant at $10 \%$; ** significant at 5\%; *** significant at $1 \%$ (two-tailed)

Eventually, I conclude that my empirics strongly and robustly suggest that cases with leadership turnover are associated with a significantly lower likelihood of ratification than agreement-state dyads in which the executive has not been replaced - given the predecessor's support for an agreement and the change in the domestic support base. New leaders with a different support base represent different constituents than their predecessors and, thus, dissimilar 
beliefs and ideas about foreign-policy decision making. In addition, their different support base allows them to escape potential "entrapment" that bound the old executive. Ultimately, given a clear signal of the preceding leader to support ratification of a treaty, ratification should be less likely with a new executive that is based on a different support base.

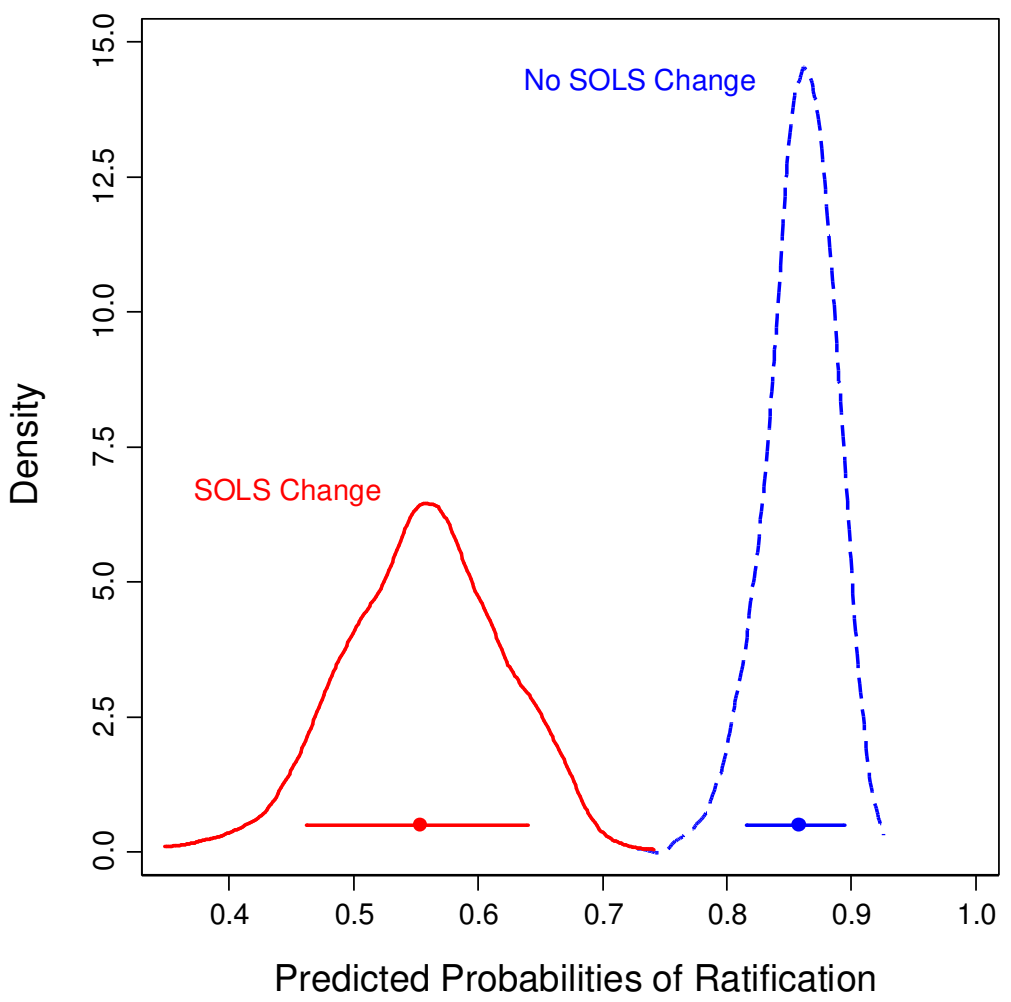

Figure 2. Predicted Probabilities of Treaty Ratification According to SOLS Change

Note: First difference estimate, i.e., the predicted probability of ratification when moving SOLS Change from its minimum (0) to its maximum (1) while holding all other variables at their median values, is at -0.302 (90 percent confidence interval: $[-0.402 ;-0.204])$. Mean point estimate of probability of ratification for SOLS Change $=0$ is at 0.858 (90 percent confidence interval: $[0.816 ; 0.895]$ ). Mean point estimate of probability of ratification for SOLS Change $=1$ is at 0.557 (90 percent confidence interval: $[0.467 ; 0.650])$. Estimates are based on simulations $(\mathrm{N}=1,000$ of simulated parameters), while holding all other variables at their median values. Horizontal bars in the figure pertain to 90 percent confidence intervals of probabilities' point estimates.

With regard to the control variables, most of them mirror previous findings in the literature. For example, as expected, Democracy has a positive impact on the likelihood of ratification: more democratic states are generally more likely to commit to international problem-solving efforts. On average, the likelihood of ratification differs by 34 percentage points when comparing 
a fully autocratic with a fully democratic state in the first year of a treaty-country spell. On the other hand, the findings for State Power reveal a significantly negative effect across my models. On average, the risk of ratification drops substantially (about 31 percentage points) if State Power is raised from its minimum to its maximum. There are also interesting results with regard to the treaty dummies, the election variable, and my measure for legislative approval. First, environmental treaties are significantly more likely than human-rights agreements to be ratified. This seems to be the case as most environmental treaties are less costly. Conversely, trade treaties are significantly less likely than human-rights agreements to be ratified. This is likely to be driven by the more complex cost-benefit structure of a trade agreement than in the case of human-rights treaties.

Legislative Approval is a variable that is associated with an effect that may not have been expected. ${ }^{12}$ That is, if legislative approval is actually required, the likelihood of ratification increases. Clearly, endogeneity might bias this finding in that, for example, leaders only ratify a treaty if they can be sure about parliamentary approval. In addition, recall that I only examine a sample of cases for which we could observe a clear signal of support (signature). As demonstrated in Model 1, however, when leaving out this variable, my core result remains unchanged. Future research might want to examine this effect more thoroughly than I could possibly do here.

Election is, as expected, negatively signed and highly significant. In the context of elections, leaders might be more careful not to lose domestic support by pursuing (foreign) policies that are less risky. Not ratifying an international agreement does not seem to be an exception here: on average, the likelihood of ratification is 6 percentage points lower in times of an election than in non-election treaty-country spells. Finally, the temporal controls show that the likelihood of

12 Note that the results are virtually identical when replacing the Legislative Approval variable by Henisz's (2000) POLCONIII measure on political constraints and veto players. 
treaty ratification first increases, then decreases, and then increases again after another, previous treaty has been ratified.

Table 3. Leadership Turnover and Treaty Ratification - Robustness Check

\begin{tabular}{|c|c|c|c|}
\hline & Model 4 & Model 5 & Model 6 \\
\hline SOLS Change & $\begin{array}{l}-2.038 \\
(0.230)^{* * *}\end{array}$ & & $\begin{array}{l}-2.628 \\
(0.311) * * *\end{array}$ \\
\hline Election & & $\begin{array}{l}-0.022 \\
(0.203)\end{array}$ & $\begin{array}{l}0.648 \\
(0.232)^{* * *}\end{array}$ \\
\hline Number of Countries Ratified & & $\begin{array}{c}0.004 \\
(0.002)\end{array}$ & $\begin{array}{l}0.009 \\
(0.002)^{* * *}\end{array}$ \\
\hline Democracy & & $\begin{array}{c}0.009 \\
(0.015)\end{array}$ & $\begin{array}{l}0.038 \\
(0.017)^{* *}\end{array}$ \\
\hline Security and Crime Treaty & & $\begin{array}{l}-0.409 \\
(0.177)^{* *}\end{array}$ & $\begin{array}{l}-0.512 \\
(0.172)^{* * *}\end{array}$ \\
\hline Environmental Treaty & & $\begin{array}{l}1.244 \\
(0.220)^{* * *}\end{array}$ & $\begin{array}{l}1.187 \\
(0.228)^{* * *}\end{array}$ \\
\hline Trade Treaty & & $\begin{array}{l}-1.075 \\
(0.244) * * *\end{array}$ & $\begin{array}{l}-0.418 \\
(0.280)\end{array}$ \\
\hline State Power & & $\begin{array}{l}-3.683 \\
(0.873)^{* * * *}\end{array}$ & $\begin{array}{l}-3.838 \\
(1.248)^{* *}\end{array}$ \\
\hline Trade Openness & & $\begin{array}{l}-0.004 \\
(0.002)^{* *}\end{array}$ & $\begin{array}{l}-0.007 \\
(0.002)^{* * *}\end{array}$ \\
\hline IGO Membership & & $\begin{array}{l}-0.009 \\
(0.005)^{*}\end{array}$ & $\begin{array}{l}-0.011 \\
(0.005)^{* *}\end{array}$ \\
\hline Legislative Approval & & $\begin{array}{l}0.384 \\
(0.223)^{*}\end{array}$ & $\begin{array}{c}0.306 \\
(0.211)\end{array}$ \\
\hline Time Since Signature & $\begin{array}{l}-0.496 \\
(0.033)^{* * *}\end{array}$ & $\begin{array}{l}-0.442 \\
(0.045) * * *\end{array}$ & $\begin{array}{l}-0.591 \\
(0.054)^{* * *}\end{array}$ \\
\hline Time Since Last Ratification & $\begin{array}{l}0.922 \\
(0.0 .423)^{* *}\end{array}$ & $\begin{array}{l}1.415 \\
(0.475)^{* * *}\end{array}$ & $\begin{array}{l}1.411 \\
(0.520)^{* * *}\end{array}$ \\
\hline Time Since Last Ratification ${ }^{2}$ & $\begin{array}{l}-0.582 \\
(0.325)^{*}\end{array}$ & $\begin{array}{l}-0.679 \\
(0.383)^{*}\end{array}$ & $\begin{array}{l}-0.749 \\
(0.401)^{*}\end{array}$ \\
\hline Time Since Last Ratification ${ }^{3}$ & $\begin{array}{c}0.049 \\
(0.046)\end{array}$ & $\begin{array}{c}0.048 \\
(0.055)\end{array}$ & $\begin{array}{c}0.058 \\
(0.056)\end{array}$ \\
\hline Constant & $\begin{array}{l}3.741 \\
(0.184)^{* * *}\end{array}$ & $\begin{array}{l}3.410 \\
(0.567)^{* * * *}\end{array}$ & $\begin{array}{l}3.992 \\
(0.681)^{* * *}\end{array}$ \\
\hline Observations & 2,447 & 2,036 & 2,036 \\
\hline Log pseudolikelihood & -881.26 & -712.27 & -621.00 \\
\hline Wald $\chi^{2}$ & $276.41 * * *$ & $240.86^{* * *}$ & $225.55 * * *$ \\
\hline Expected Percent Correctly Predicted & 0.78 & 0.78 & 0.81 \\
\hline Expected Proportional Reduction in Error & 0.32 & 0.30 & 0.40 \\
\hline $\operatorname{AIC}(* N)$ & $1,774.51$ & $1,454.55$ & $1,274.00$ \\
\hline
\end{tabular}

Note: Robust standard errors clustered on country in parentheses.

* significant at 10\%; ** significant at 5\%; *** significant at 1\% (two-tailed)

As indicated above, the Supplementary Materials summarize a series of robustness checks. An additional analysis that seems worth presenting already here pertains to the time elapsed between 
signature and SOLS change. It has been suggested that leadership turnover could merely be an artifact of treaties that are very difficult to ratify and, as such, take longer to achieve ratification. One way to address this concern is to include a control measuring the amount of time elapsed between signature and leader turnover (if any). Table 3 presents the corresponding results and, as demonstrated there, the core finding remains robust. All other robustness checks and additional analyses can be found in the Supplementary Materials.

\section{Conclusion}

Leaders are ultimately responsible for their country's foreign policy and the ratification of international treaties is clearly part of this. But what role do leaders really play within this context? This article sought to contribute to clarifying this. By focusing on leadership change and, more specifically, the replacement of a government leader by a new one who relies on different social groups for support, I developed a theoretical framework that systematically examines the relationship of leadership turnover and the likelihood of ratifying international agreements in light of a predecessor's clearly signaled support for an international agreement. Empirically, I analyzed recently compiled data on multilateral treaties that have been concluded in the post-Cold War era.

First, changes in the political leadership of a country matter for ratification decisions. My theory took into account support for a treaty issued by an executive before the replacement of the leader and showed that we would expect that an incoming leader might be more hesitant to ratify that agreement. In turn, the likelihood of ratification goes down. The hypothesis receives robust empirical support, and my work correspondingly highlights the importance of domestic-level, "first-image" variables (Chiozza and Choi 2003: 275), and the strong connection between domestic and international politics, which further mirrors the notion by Goemans et al. (2009) 
that the scholarly work is well advised to move beyond still prevalent state-centric perspectives (see also Wolford 2007, 2012; Mattes et al. 2015). States are not unitary actors and the need is still given to further study their role in international relations and comparative politics in a more disaggregated way. In the words of Chiozza and Choi (2003: 275): "leaders' type cannot remain an all-encompassing category if it is to be of any use in empirical research." This claim stated more than ten years ago is no less relevant today, and it is my hope that several crucial policy implications and avenues for further research might emerge from my work.

Second, the ratification decision is based on a cost-benefit analysis of leaders. My research sought to increase our understanding of leader-related factors within this analysis, thus allowing policymakers now to take these factors specifically into account when negotiating treaties. As new leaders seem particularly associated with a significantly lower likelihood of ratification, additional benefits and incentives should perhaps be introduced into a treaty framework to increase state participation. When encountering leaders in negotiations over international agreements who might signal that they are reluctant to ratify, this research could shed light on the reasons for why this is the case.

Third, from a scholarly perspective, my framework applies to democracies and nondemocracies alike. That being said, the level of accountability is clearly lower in autocratic states than in democracies (Gandhi and Przeworski 2006). And while there is some evidence for an interaction with the democracy item as demonstrated in the Supplementary Materials, future research might focus more strongly on autocratic leaders, the associated factors within nondemocratic states, as well as the differences across autocracies and democracies that may then shape the impact of leader turnover in diverse ways. In addition, although I have identified a general pattern in the relationship between leadership turnover and treaty ratification, there are plenty of cases that deviate from this pattern. Consider the Convention on Protection of Children 
and Co-operation in Respect of Intercountry Adoption and the United Nations Convention against Transnational Organized Crime. Germany signed the former in 1997 and there was a SOLS change in 1998 (a coalition led by the Social Democrats assuming power); but the new government still ratified the agreement in 2001. In terms of the second treaty, the US signed it under Bill Clinton in 2000, but it was the Bush administration that ratified it in 2005. As a result, it seems an effort worth making to examine ratifications, which occur despite a leadership turnover and despite a signature from a predecessor government, in future research, as these are precisely the cases that deviate from the general pattern I have uncovered. In that sense, it is also my hope that my project, as the first one on that subject, will lead to several other studies in this promising field of research.

Finally, more disaggregated analyses might be necessary, also with regard to democracies. It is indeed plausible that particular forms of democratic government (presidential vs. parliamentary systems; see Bang et al. 2012) reinforce the effects I argue for. There are also many examples of "cohabitation" or divided government, where different parties dominate the executive and the legislative. Future research should address this and related issues within the nexus of treaty ratification and political leadership.

\section{References}

Baccini, Leonardo, and Johannes Urpelainen. 2014. Before Ratification: Understanding the Timing of International Treaty Effects on Domestic Policies. International Studies Quarterly 58(1): 29-43.

Bang, Guri, Jon Hovi, and Detlef Sprinz. 2012. US Presidents and the Failure to Ratify Multilateral Environmental Agreements. Climate Policy 12(6): 755-763. 
Bernauer, Thomas, Tobias Böhmelt, and Vally Koubi. 2013. Is There a Democracy-Civil Society Paradox in Global Environmental Governance? Global Environmental Politics 13(1): 88-107. Bernauer, Thomas, Anna Kalbhenn, Vally Koubi, and Gabriele Spilker. 2010. A Comparison of International and Domestic Sources of Global Governance Dynamics. British Journal of Political Science 40(3): 509-538.

Bobick, Talya, and Alastair Smith. 2013. The Impact of Leader Turnover on the Onset and the Resolution of WTO Disputes. Review of International Organizations 8(4): 423-445.

Brender, Adi, and Allan Drazen. 2005. Political Budget Cycles in New versus Established Democracies. Journal of Monetary Economics 52(7): 1271-1295.

Bueno de Mesquita, Bruce, Alastair Smith, Randolph Siverson, and James D. Morrow. 2003. The Logic of Political Survival. Cambridge, MA: MIT Press.

Carter, David B., and Curtis S. Signorino. 2010. Back to the Future: Modeling Time Dependency in Binary Data. Political Analysis 18(3): 271-292.

Cazals, Antoine, and Alexandre Sauquet. (2015). How Do Elections Affect International Cooperation? Evidence from Environmental Treaty Participation. Public Choice 162(3): 263285.

Chiozza, Giacomo, and Ajin Choi. 2003. Guess Who Did What. Political Leaders and the Management of Territorial Disputes, 1950-1990. Journal of Conflict Resolution 47(3): 251278.

Chiozza, Giacomo, and Hein Goemans. 2004. International Conflict and the Tenure of Leaders: Is War Still Ex-Post Inefficient? American Journal of Political Science 48(3): 604-619.

Clarke, Kevin A. 2005. The Phantom Menace: Omitted Variable Bias in Econometric Research. Conflict Management and Peace Science 22(4): 341-352. 
Clarke, Kevin A. 2009. Return of the Phantom Menace: Omitted Variable Bias in Political Research. Conflict Management and Peace Science 26(1): 46-66.

Cranmer, Skyler, Bruce A. Desmarais, and Elizabeth J. Menninga. 2012. Complex Dependencies in the Alliance Network. Conflict Management and Peace Science 29(3): 279-313.

Croco, Sarah. 2011. The Decider's Dilemma: Leader Culpability, War Outcomes, and Domestic Punishment. American Political Science Review 105(3): 457-477.

Debs, Alexandre, and Hein Goemans. 2010. Regime Type, the Fate of Leaders, and War. American Political Science Review 104(3): 430-445.

Downs, Anthony. 1957. An Economic Theory of Democracy. New York: Harper.

Elsig, Manfred, Karolina Milewicz, and Nikolas Stürchler. 2011. Who Is In Love with Multilateralism? Treaty Commitment in the Post-Cold War Era. European Union Politics 12(4): 529-550.

Erikson, Robert S., Pablo M. Pinto and Kelly T. Rader. 2009. Dirty Pool Revisited: When Less Is More. Paper presented at the 2009 meeting of the American Political Science Association.

Franzese, Robert, and Jude Hays. 2007. Spatial Econometric Models of Cross-Sectional Interdependence in Political Science Panel and Time-Series-Cross-Section Data. Political Analysis 15(2): 140-164.

Fredriksson, Per, and Noel Gaston. 2000. Ratification of the 1992 Climate Change Convention: What Determines Legislative Delay? Public Choice 104(3/4): 345-368.

Fredriksson, Per, Eric Neumayer, and Gergely Ujhelyi. 2007. Kyoto Protocol Cooperation: Does Government Corruption Facilitate Environmental Lobbying? Public Choice 133(1/2): 231251.

Gandhi, Jennifer, and Adam Przeworski. 2006. Cooperation, Cooptation, and Rebellion under Dictatorships. Economics and Politics 18(1): 1-26. 
Goemans, Hein. 2000. War and Punishment: The Causes of War Termination and the First World War. Princeton, NJ: Princeton University Press.

Goemans, Hein, Kristian Skrede Gleditsch, and Giacomo Chiozza. 2009. Introducing Archigos: A Dataset of Political Leaders. Journal of Peace Research 46(2): 269-283.

Hathaway, Oona. 2007. Why Do Countries Commit to Human Rights Treaties? Journal of Conflict Resolution 51(4): 588-621.

Henisz, Witold J. 2000. The Institutional Environment for Economic Growth. Economics \& Politics 12(1): 1-31.

Herron, Michael C. 2000. Postestimation Uncertainty in Limited Dependent Variable Models. Political Analysis 8(1): 83-98.

Hollyer, James R., and B. Peter Rosendorff. 2012. Leadership Survival, Regime Type, Policy Uncertainty, and PTA Accession. International Studies Quarterly 56(4): 748-764.

Hugh-Jones, David, Karolina Milewicz, and Hugh Ward. 2016. Signaling by Signature: The Weight of International Opinion and Ratification of Treaties by Domestic Veto Players. Political Science Research and Methods: Forthcoming.

King, Gary, Michael Tomz, and Jason Wittenberg. 2000. Making the Most of Statistical Analyses: Improving Interpretation and Presentation. American Journal of Political Science 44(2): 347-361.

Leeds, Brett Ashley. 2003. Alliance Reliability in Times of War: Explaining State Decisions to Violate Treaties. International Organization 57(4): 801-827.

Levy, Jack. 1994. Learning and Foreign Policy: Sweeping a Conceptual Minefield. International Organization 48(2): 279-312.

Lupu, Yonatan. 2015. Legislative Veto Players and the Effects of International Human Rights Agreements. American Journal of Political Science 59(3): 578-594. 
Lupu, Yonatan. 2016. Why Do States Join Some Universal Treaties but Not Others? An Analysis of Treaty Commitment Preferences. Journal of Conflict Resolution 60(7): 1219-1250.

Mansfield, Edward D., Helen V. Milner, and Jon C. Pevehouse. 2007. Vetoing Co-operation: The Impact of Veto Players on Preferential Trading Arrangements. British Journal of Political Science 37(3): 403-432.

Mansfield, Edward D., Helen V. Milner, and Jon C. Pevehouse. 2008. Democracy, Veto Players and the Depth of Regional Integration. The World Economy 31(1): 67-96.

Mansfield, Edward D., Helen V. Milner and B. Peter Rosendorff. 2002. Why Democracies Cooperate More: Electoral Control and International Trade Agreements. International Organization 56(3): 477-513.

Marshall, Monty, and Keith Jaggers. 2004. Polity IV Project: Political Regime Characteristics and Transitions 1800-2004, Dataset Users' Manual. Boulder, CO: Colorado State University Center for Global Policy School of Public Policy.

Martin, Lisa. 1993. Credibility, Costs, and Institutions. Cooperation on Economic Sanctions. World Politics 45(3): 406-432.

Mattes, Michaela, Brett Ashley Leeds, and Royce Carroll. 2015. Leadership Turnover and Foreign Policy Change: Societal Interests, Domestic Institutions, and Voting in the United Nations. International Studies Quarterly 59(2): 280-290.

Mattes, Michaela, Brett Ashley Leeds, and Naoko Matsumura. 2016. Measuring Change in Source of Leader Support: The CHISOLS Dataset. Journal of Peace Research 53(2): 259-267. McGillivray, Fiona, and Allan C. Stam. 2004. Political Institutions, Coercive Diplomacy, and the Duration of Economic Sanctions. Journal of Conflict Resolution 48(2): 154-172.

McGillivray, Fiona, and Alastair Smith. 2004. The Impact of Leadership Turnover on Trading Relations among States. International Organization 58(3): 567-600. 
McGillivray, Fiona, and Alastair Smith. 2008. Punishing the Prince: A Theory of Interstate Relations, Political Institutions, and Leadership Change. Princeton, NJ: Princeton University Press.

Milewicz, Karolina, and Manfred Elsig. 2014. The Hidden World of Multilateralism: Treaty Commitments of Newly Democratized States in Europe. International Studies Quarterly 58(2): 322-335.

Nordhaus, William. 1975. The Political Business Cycle. Review of Economic Studies 42(2): 169190.

Neumayer, Eric. 2002a. Do Democracies Exhibit Stronger International Environmental Commitment? A Cross-Country Analysis. Journal of Peace Research 39(2): 139-164.

Neumayer, Eric. 2002b. Does Trade Openness Promote Multilateral Environmental Cooperation? World Economy 25(6): 815-832.

Neumayer, Eric. 2003. Are Left-Wing Party Strength and Corporatism Good for the Environment? Evidence from Panel Analysis of Air Pollution in OECD Countries. Ecological Economics 45(2): 203-220.

Neumayer, Eric. 2004. The Environment, Left-Wing Political Orientation, and Ecological Economics. Ecological Economics 51(3-4): 167-175.

Pevehouse, Jon, Timothy Nordstrom, and Kevin Warnke. 2004. The COW-2 International Organizations Dataset Version 2.0. Conflict Management and Peace Science 21(2): 101-119.

Pilster, Ulrich, Tobias Böhmelt, and Atsushi Tago. 2015. Political Leadership Changes and the Withdrawal from Military Coalition Operations, 1946-2001. International Studies Perspectives 16(4): 463-483.

Putnam, Robert. 1988. Diplomacy and Domestic Politics: The Logic of Two-Level Games. International Organization 42(3): 427-460. 
Quiroz Flores, Alejandro. 2012. A Competing Risks Model of War Termination and Leader Change. International Studies Quarterly 56(4): 809-819.

Roberts, J. Timmons, Bradley C. Parks, and Alexis A. Vásquez. 2004. Who Ratifies Environmental Treaties and Why? Institutionalism, Structuralism, and Participation by 192 Nations in 22 Treaties. Global Environmental Politics 4(3): 22-64.

Roeder, Philip G. 1985. Do New Soviet Leaders Really Make a Difference? Rethinking the “Succession Connection.” American Political Science Review 79(4): 958-976.

Saunders, Elizabeth. 2009. Transformative Choices: Leaders and the Origins of Intervention Strategy. International Security 34(2): 119-161.

Schelling, Thomas C. 1960. The Strategy of Conflict. Cambridge, MA: Harvard University Press.

Schneider, Christina J., and Johannes Urpelainen. 2013. Distributional Conflict between Powerful States and International Treaty Ratification. International Studies Quarterly 57(1): $13-27$.

Schultz, Kenneth A. 2005. The Politics of Risking Peace: Do Hawks or Doves Deliver the Olive Branch? International Organization 59(1): 1-38.

Shi, Min, and Jakob Svensson. 2006. Political Budget Cycles: Do They Differ Across Countries and Why? Journal of Public Economics 90(8-9): 1367-1389.

Smith, Alastair. 2016. Leader Turnover, Institutions, and Voting at the UN General Assembly. Journal of Conflict Resolution 60(1): 143-163.

Smith, Alastair, and David Hayes. 1997. The Shadow of the Polls: Electoral Effects on International Agreements. International Interactions 23(1): 79-108.

Spilker, Gabriele. 2013. Globalization, Political Institutions, and the Environment in Developing Countries. New York: Routledge. 
Spilker, Gabriele, and Vally Koubi 2016. The Effects of Treaty Legality and Domestic Institutional Hurdles on Environmental Treaty Ratification. International Environmental Agreements 16(2): 223-238.

Stanley, Elizabeth. 2009. Ending the Korean War: The Role of Domestic Coalition Shifts in Overcoming Obstacles to Peace. International Security 34(1): 42-82.

Stanley, Elizabeth, and John P. Sawyer. 2009. The Equifinality of War Termination: Multiple Paths to Ending War. Journal of Conflict Resolution 53(5): 651-676.

Vertzberger, Yaacov. 1998. Risk Taking and Decisionmaking: Foreign Military Intervention Decisions. Stanford, CA: Stanford University Press.

von Stein, Jana. 2008. The International Law and Politics of Climate Change. Journal of Conflict Resolution 52(2): 243-268.

Walker, Stephen G. 1983. The Motivational Foundations of Political Belief Systems: A ReAnalysis of the Operational Code Construct. International Studies Quarterly 27(2): 179-202.

Wangler, Leo, Juan-Carlos Altamirano-Cabrera, and Hans-Peter Weikard. 2013. The Political Economy of International Environmental Agreements: A Survey. International Environmental Agreements 13(3): 387-403.

Wolford, Scott. 2007. The Turnover Trap: New Leaders, Reputation, and International Conflict. American Journal of Political Science 51(4): 772-788.

Wolford, Scott. 2012. Incumbents, Successors, and Crisis Bargaining: Leadership Turnover as a Commitment Problem. Journal of Peace Research 49(4): 517-530.

Wolford, Scott, and Emily Hencken Ritter. 2016. National Leaders, Political Security, and the Formation of Military Coalitions. International Studies Quarterly 60(3): 540-551. 
Yamagata, Yoshiki, Jue Yang, and Joseph Galaskiewicz. 2013. A Contingency Theory of Policy Innovation: How Different Theories Explain the Ratification of the UNFCCC and Kyoto Protocol. International Environmental Agreements 13(2): 251-270. 


\section{International Treaty Ratification and Leader Turnover -}

\section{Supplementary Materials}

The Supplementary provide additional information, analyses, and robustness checks that further support my argument and findings of the main article. These include:

- Examining only country-treaty spells of short durations.

- Instead of robust standard errors clustered by country, I have re-estimated the core model using bootstrapped standard errors based on 1,000 replications.

- Due to the similarity of binary time-series cross-section data and discrete duration data, I also employed Cox proportional hazards models.

- I present Cox proportional hazards and logistic regression models that have the treaty-country year as the unit of analysis.

- I examined a potential interaction between the democracy variable and SOLS Change.

- A last robustness check incorporates country-fixed effects to capture any unobserved time-invariant unit-level effects.

- I present the main models' separation plots.

- I provide an overview of which international treaties are included in the data set.

\section{Treaty-Country Spells of Short Durations}

As discussed in the main text, I decided to rely on the treaty-country pair as the unit of analysis. To this end, I used the starting values for some of the covariates (e.g., the democracy item), while other variables are based on their values at the end of each spell. Most importantly, my main explanatory item, SOLS Change, captures only one, if any, leadership turnover and we also know that such a change, if any, occurred after signature and before a ratification (if any). My main 
argument in the main article is that such a data structure does not artificially inflate the number of observations and it effectively addresses concerns regarding endogeneity. However, a reasonable objection to this research design could be that the duration of the treaty-country spells might then be too long, which would induce that the actual effects of some covariates are severely temporally lagged.

Table A1. Leadership Turnover and Treaty Ratification - Logistic Regression

\begin{tabular}{ll}
\hline & Model A1 \\
\hline SOLS Change & -2.284 \\
& $(0.509)^{* * *}$ \\
Election & 0.509 \\
& $(0.344)$ \\
Number of Countries Ratified & 0.033 \\
& $(0.003)^{* * *}$ \\
Democracy & 0.070 \\
& $(0.024)^{* * *}$ \\
Security and Crime Treaty & -18.41 \\
& $(0.292)^{* * *}$ \\
State Power & -5.384 \\
& $(1.339)^{* * *}$ \\
Trade Openness & -0.012 \\
& $(0.002)^{* * *}$ \\
IGO Membership & -0.019 \\
& $(0.007)^{* * * *}$ \\
Legislative Approval & -0.204 \\
& $(0.323)$ \\
Constant & 20.772 \\
& $(0.764)^{* * *}$ \\
Observations & 957 \\
Log pseudolikelihood & -215.62 \\
Wald $\chi^{2}$ & $170.06 * * *$ \\
AIC $(* N)$ & 455.23 \\
\hline
\end{tabular}

Note: Robust standard errors clustered on country in parentheses. Environmental Treaty and Trade Treaty dropped as they predict ratification perfectly. Variables for temporal correction included, but omitted from presentation.

* significant at $10 \%$; * significant at $5 \%$; ** significant at $1 \%$ (two-tailed)

Treat-country spells in my data set range from 0.5 to 18 years, with an average duration of 4.34 years. To illustrate the problem more clearly, consider the spells that have a duration of 18 years (0.34 percent of the cases in my sample): the effect of the covariates based on initial values is supposed to be present over the entire duration of 18 years, while the only leadership turnover 
that may have occurred in, say, the third year of that spell is meant to have an almost equally long impact on the likelihood of treaty ratification. Moreover, consider a treaty that becomes open for ratification in 1992 and nations $a$ and $b$. Suppose that $a$ signed in 1992 and ratified in 1998, but $b$ never ratified after having signed in, say, 1992 as well. For SOLS Change, it would be coded as 1 if leader change occurred between 1993 and 1997 in the case of nation $a$, and coded as 1 if leader change changed occurred between 1993 and 2008 in nation $b$. However, there may be a greater possibility of leader change in $b$ and, therefore, leader change and ratification delay are correlated. In order to deal with this issue, I dropped a series of cases from the data as I only kept those treaty-country spells in my sample that have shorter than average durations (i.e., less than 4.34 years). This ensures that the effects of my core variable and the other covariates are not based on seemingly long temporal lags, which could induce spurious relationships.

Table A1 summarizes my findings. The sample size obviously decreases by quite a bit to 957 spells as more than 50 percent of the cases leave the estimation sample. That being said, the results presented in Table A1 are virtually identical to those discussed in the main text: SOLS Change exerts a negative and statistically significant impact on the likelihood of treaty ratification.

\section{Bootstrapped Standard Errors}

All models are based on maximum likelihood estimation (MLE), which has desirable asymptotic properties such as consistency, efficiency, or normality (King and Zeng 2001). However, these properties might not be given and MLE estimates can be biased particularly when there are only a few cases to analyze. While this may not necessarily be an issue in my setup, I aggregate treatycountry years into spells and, in fact, there is no specific rule, which determines when a sample is "small”' or "large." To this end, I considered bootstrapping the standard errors. 
Table A2. Leadership Turnover and Treaty Ratification - Logistic Regression

\begin{tabular}{ll}
\hline & Model A2 \\
\hline SOLS Change & -1.588 \\
& $(0.161)^{* * *}$ \\
Election & -0.701 \\
& $(0.166)^{* * *}$ \\
Number of Countries Ratified & 0.001 \\
& $(0.002)$ \\
Democracy & 0.097 \\
& $(0.012)^{* * *}$ \\
Security and Crime Treaty & -0.116 \\
& $(0.170)$ \\
Environmental Treaty & 1.442 \\
& $(0.223)^{* * *}$ \\
Trade Treaty & -0.571 \\
& $(0.180)^{* * *}$ \\
State Power & -3.252 \\
& $(1.095)^{* * *}$ \\
Trade Openness & -0.004 \\
& $(0.001)^{* * *}$ \\
IGO Membership & -0.017 \\
& $(0.004)^{* * *}$ \\
Legislative Approval & 0.334 \\
Constant & $(0.163)^{* *}$ \\
Observations & 2.794 \\
Log pseudolikelihood & $(0.405)^{* * *}$ \\
Wald $\chi^{2}$ & 2,221 \\
AIC (*N) & -844.15 \\
& $298.07 * * *$ \\
& $1,718.29$ \\
\hline
\end{tabular}

Note: Bootstrapped standard errors in parentheses (1,000 replications). Variables for temporal correction included, but omitted from presentation.

* significant at 10\%; ** significant at 5\%; *** significant at 1\% (two-tailed)

According to Guan (2003: 71), “[b]ootstrapping is a nonparametric approach for evaluating the distribution of a statistic based on random re-sampling." The procedure is based on random sample draws (with replacement) repeatedly from the sample data. I specify 1,000 as the number of random draws and calculated the parameters for my main model again. The results are summarized in Table A2: clearly, the coefficient estimates are identical to those presented in the main text's core model, only the standard errors change. However, the standard error pertaining to SOLS Change actually decreases in size, which implies that the overall conclusion based on this variable does not change. 


\section{Cox Duration Model}

Time-series cross-section data using a binary dependent variable, which I rely on for the main analyses, are similar to discrete duration data (Beck et al. 1998). Duration models, i.e., estimators modeling the time elapsed until an even occurs as a function of covariates, might be an alternative estimation procedure then. To this end, I re-define the dependent variable as the time (in years) between the date when an international treaty becomes open for ratification and the date a country ratifies that agreement (or the end of the observation period in case ratification did not occur). In other words, I use the duration of a treaty-country spell as the outcome variable in the following alternative model setup.

Concentrating on duration is based on the assumption that the differences in time that countries need to ratify an agreement reflect their - and leaders' - relative preference intensities. More rapid ratification signals a stronger commitment to international cooperation (see also Fredriksson and Gaston 2000; Elsig et al. 2011; Bernauer et al. 2013; Milewicz and Elsig 2014). This approach has also econometric advantages as it may give more variation across countries than simply estimating the likelihood of whether a country ratified or not (Schneider and Urpelainen 2013) and I can consider the different time lags that are characteristic for states' decisions in this regard (Elsig et al. 2011: 540).

Since I do not impose a particular functional form on the baseline hazard of ratifying an agreement, I use Cox proportional hazards models. This leaves the duration dependency unspecified and focuses the empirical analysis on how the covariates shift the baseline hazard. I examined the Schoenfeld residuals for a violation of the proportionality assumption, which showed that this assumption is indeed not met for some of my covariates across the models. Thus, I include interaction terms for all explanatory variables with the natural logarithm of time 
(Box-Steffensmeier and Zorn 2001; Box-Steffensmeier et al. 2003; Box-Steffensmeier and Jones 2004: 131ff).

Table A3. Leadership Turnover and Treaty Ratification - Cox Duration Models

\begin{tabular}{ll}
\hline & Model A3 \\
\hline SOLS Change & -0.994 \\
& $(0.110)^{* * *}$ \\
Election & -1.036 \\
& $(0.081)^{* * *}$ \\
Number of Countries Ratified & -0.009 \\
& $(0.001)^{* * *}$ \\
Democracy & 0.054 \\
& $(0.006)^{* * *}$ \\
State Power & -2.061 \\
& $(1.640)$ \\
Trade Openness & -0.001 \\
& $(0.001)$ \\
IGO Membership & -0.010 \\
& $(0.002)^{* * *}$ \\
Legislative Approval & -0.036 \\
& $(0.078)$ \\
Observations & 2,221 \\
Log pseudolikelihood & $-9,820.76$ \\
Wald $\chi^{2}$ & $667.65 * * *$ \\
AIC $(* \mathrm{~N})$ & $19,657.52$ \\
\hline
\end{tabular}

Note: Robust standard errors clustered on country in parentheses. Efron method for ties. Table entries are nonexponentiated coefficients. Treaty issue areas used as strata and, thus, not included as covariates.

* significant at $10 \%$;* significant at $5 \%$;** significant at $1 \%$ (two-tailed)

I fit stratified Cox models. This stratification approach allows that baseline hazard functions are estimated for each stratum separately. For example, Neumayer $(2003,2004)$ demonstrates that governmental parties' support for international cooperation efforts might depend on their political ideology and the type of an agreement. The reason for this is that "pro-environmental policies complement distributional concerns and skepticism toward the beneficial effects of unregulated markets, which are traditionally regarded as separating the political left from the political right“ (Neumayer 2004: 167; see also Dunlap et al. 2001). Leaders, under some circumstances, might therefore be more likely to ratify environmental agreements, but not international trade or security treaties. Following Elsig et al. (2011; see also Milewicz and Elsig 
2014), I use the treaties' underlying issue areas (human rights, environment, security, and trade) as strata, which then control for the fact that the salience of treaties in my sample is likely to vary over issue area and, consequently, for the cost-benefit analysis of leaders. As in the main text, the data for these four strata, i.e., Human Rights Treaty, Security and Crime Treaty, Environmental Treaty, and Trade Treaty, are also taken from Elsig et al. (2011) and Milewicz and Elsig (2014).

I report non-exponentiated coefficients, where higher values for an explanatory variable signify faster ratification, i.e., positive coefficients indicate an increasing hazard. I also cluster the standard errors on the country level for taking into account intra-group correlations.

Table A3 emphasizes that changing the estimator does not have any impact on the results as such. We still obtain a negative impact of SOLS Change on the likelihood of ratification as demonstrated by this item's negative non-exponentiated coefficient in Model A3: in other words, therefore, a SOLS change in fact delays ratification.

\section{Using the Treaty-Country-Year as the Unit of Analysis}

In order to show that the aggregation of treaty-country years into treaty-country spells, however plausible and reasonable it may seem for addressing the concerns discussed in the main text, does not affect the substance of my findings, Table A4 relies on the "disaggregated" treaty-country year as the unit of analysis. As a result, all covariates are based on the actual year values and not, as in the main text, on spell-start or spell-end year values. Table A4 presents two different specifications: one based on a Cox model (Model A4) and a second that is based on a logistic regression model (Model A5). However, Table A4 underlines that the unit of analysis does not affect my results either: while the number of observations increases to more than $8,000, S O L S$ Change remains negatively signed and highly statistically significant. 
Table A4. Leadership Turnover and Treaty Ratification - Cox Duration and Logistic Regression

\begin{tabular}{lll}
\hline & Model A4 & Model A5 \\
\hline SOLS Change & -0.914 & -1.118 \\
Election & $(0.086)^{* * *}$ & $(0.110)^{* * *}$ \\
& 0.041 & 0.020 \\
Number of Countries Ratified & $(0.130)$ & $(0.080)$ \\
& 0.032 & 0.022 \\
Democracy & $(0.002)^{* * *}$ & $(0.001)^{* * *}$ \\
& 0.029 & 0.075 \\
Security and Crime Treaty & $(0.010)^{* * *}$ & $(0.009)^{* * *}$ \\
& & 0.147 \\
Environmental Treaty & & $(0.094)$ \\
& & 0.166 \\
Trade Treaty & & $(0.120)$ \\
& & 0.255 \\
State Power & & $(0.159)$ \\
Trade Openness & -1.842 \\
IGO Membership & $(1.034$ & $(1.029)^{*}$ \\
& -0.001 & -0.001 \\
Legislative Approval & $(0.002)$ & $(0.001)$ \\
Constant & 0.006 & 0.001 \\
Observations & $(0.004)$ & $(0.003)$ \\
Log pseudolikelihood & -0.143 & 0.117 \\
Wald $\chi^{2}$ & $(0.178)$ & $(0.115)$ \\
AIC $(* N)$ & & -3.213 \\
& & $(0.298)^{* * *}$ \\
& & 8,263 \\
& $-3,263$ & $566.15 * * *$ \\
& $770.36 * * *$ & $6,821.05$ \\
\hline
\end{tabular}

Note: Robust standard errors clustered on country in parentheses. Variables for temporal correction included, but omitted from presentation.

* significant at $10 \%$; ** significant at 5\%; *** significant at $1 \%$ (two-tailed)

\section{Interaction between the Democracy Variable and SOLS Change}

I additionally examine the possibility that the effect of leadership change might vary by regime type and, thus, interact SOLS Change with the democracy item. This seems crucial due to the importance of domestic institutions for the ratification decision and because the level of domestic support is also a function of the size of a country's winning coalition, which is highly correlated with democracy (Bueno de Mesquita et al. 2003). Moreover, from a theoretical perspective, Croco (2011: 463) argues that democratic institutions facilitate removing a political leader, while Mattes et al. (2015: 282f) contend that democracies are based on policymaking rules that 
"discourage dramatic change in policy." Including the multiplicative term of SOLS Change and Democracy captures the following conditional effect of leader change on the likelihood of treaty ratification (see also Mattes et al. 2015: 187). As we cannot directly interpret the size, signs, and standard errors of the components of a multiplicative specification (Brambor et al. 2006), I calculate the average marginal effects of SOLS Change according to Democracy to allow for a substantive interpretation. Table A5 and Figure A1 summarizes the corresponding results.

Table A5. Leadership Turnover and Treaty Ratification - Logistic Regression

\begin{tabular}{ll}
\hline & Model A6 \\
\hline SOLS Change & -1.578 \\
& $(0.352)^{* * *}$ \\
Election & -0.701 \\
& $(0.190)^{* * *}$ \\
Number of Countries Ratified & 0.001 \\
& $(0.002)$ \\
Democracy & 0.097 \\
& $(0.017)^{* * *}$ \\
SOLS Change * Democracy & -0.001 \\
& $(0.045)$ \\
Security and Crime Treaty & -0.116 \\
& $(0.159)$ \\
Environmental Treaty & 1.441 \\
& $(0.229)^{* * *}$ \\
Trade Treaty & -0.571 \\
& $(0.190)^{* * *}$ \\
State Power & -3.249 \\
& $(1.615)^{* *}$ \\
Trade Openness & -0.004 \\
& $(0.002)^{* *}$ \\
IGO Membership & -0.017 \\
Legislative Approval & $(0.004)^{* * *}$ \\
Constant & 0.334 \\
Observations & $(0.193)^{*}$ \\
Log pseudolikelihood & 2.792 \\
Wald $\chi^{2}$ & $(0.522)^{* * *}$ \\
AIC $(* N)$ & 2,221 \\
& -844.145 \\
& $187.47 * * *$ \\
& $1,720.29$ \\
\hline & \\
&
\end{tabular}

Note: Robust standard errors clustered on country in parentheses. Variables for temporal correction included, but omitted from presentation.

* significant at $10 \%$; * significant at 5\%; *** significant at $1 \%$ (two-tailed) 


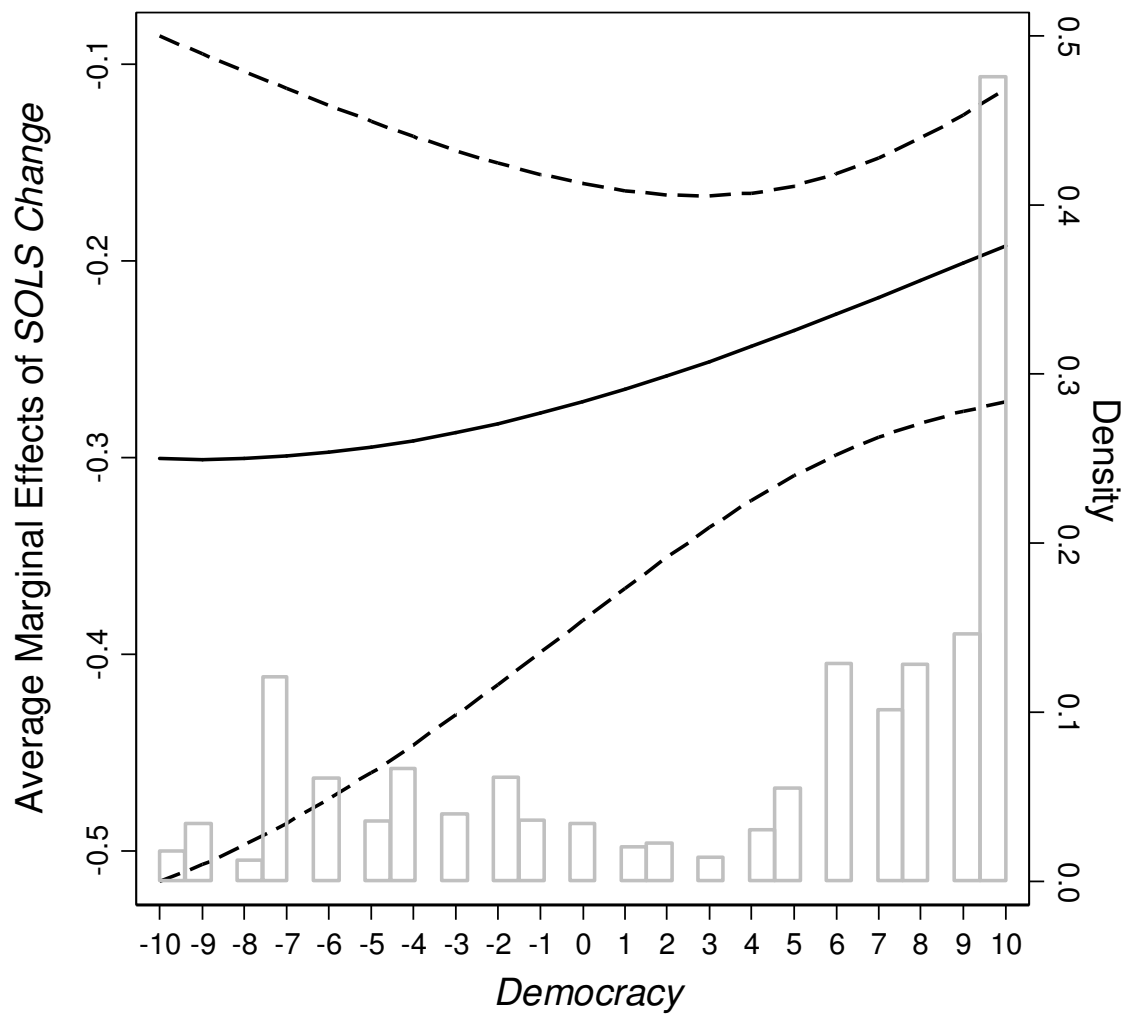

Figure A1. The Impact of Political Leadership Turnover Conditional on Regime Type

Note: Panel shows average marginal effects (solid line) based on logistic regression model estimates (Table A5), while all other variables are held at their mean values. Dashed lines pertain to 90 percent confidence intervals. Histogram of Democracy shows the distribution of this item (right-hand side vertical axis).

Figure A1 highlights that there is not much evidence for an impact of SOLS Change conditional on regime type. Having said that, future work could try to offer more nuanced explanations by concentrating on the variation within system types, e.g., presidential vs. parliamentary systems.

\section{Controlling for Unobserved Country Characteristics: Fixed Effects Estimation}

Country fixed effects address any unobserved, time-invariant country characteristics I may have omitted in the study's main analyses. By including them, I also address any remaining endogeneity concerns. That is, I discussed and addressed several issues of endogeneity in this 
research, but endogeneity between my core explanatory variable and ratification may persist. For example, the ratification of an international treaty can be both a contributor to and consequence of leadership turnover. I use fixed effects for countries to deal with this problem, which control for omitted variable bias and unobserved heterogeneity, as they address the unobserved variables that may lead to "self-selection" into, e.g., leadership transitions and SOLS changes.

Table A6. Leadership Turnover and Treaty Ratification - Logistic Regression

\begin{tabular}{ll}
\hline & Model A7 \\
\hline SOLS Change & -2.668 \\
& $(0.409)^{* * *}$ \\
Election & -1.359 \\
& $(0.259)^{* * *}$ \\
Number of Countries Ratified & 0.006 \\
& $(0.002)^{* *}$ \\
Democracy & -0.019 \\
& $(0.076)$ \\
Security and Crime Treaty & -0.185 \\
& $(0.202)$ \\
Environmental Treaty & 1.348 \\
& $(0.291)^{* * *}$ \\
Trade Treaty & -0.976 \\
& $(0.279)^{* * *}$ \\
State Power & -4.696 \\
& $(9.700)$ \\
Trade Openness & -0.035 \\
& $(0.010)^{* * *}$ \\
IGO Membership & -0.177 \\
& $(0.037)^{* * *}$ \\
Legislative Approval & -1.648 \\
& $(4.380)$ \\
Constant & 23.143 \\
& $(4.102)^{* * *}$ \\
Observations & 1,903 \\
Log pseudolikelihood & -631.85 \\
Wald $\chi^{2}$ & $693.41 * * *$ \\
AIC (*N) & $1,287.69$ \\
\hline &
\end{tabular}

Note: Robust standard errors clustered on country in parentheses. Country fixed effects and variables for temporal correction included, but omitted from presentation.

* significant at $10 \%$;* significant at 5\%; *** significant at $1 \%$ (two-tailed)

Table A6 (Model A7) presents the findings for this last robustness check. First, some of the particularly largely time-invariant predictors (e.g., Democracy) are no longer statistically significant at conventional levels in my model. The poor performance of the control variables can 
be explained by the fact that fixed-effects models lack the ability to make inferences about timeinvariant or slow-moving variables, because fixed effects soak up most of the explanatory power of slowly changing variables and their coefficients are either not identified or difficult to estimate with precision (Beck 2001: 285; Plümper and Troeger 2007). However, SOLS Change remains negatively signed and substantively important. The replacement of a government leader by a new one who relies on different social groups for support thus continues to have a negative impact on the likelihood of ratifying an international treaty.

\section{Main Models' Separation Plots}

In light of the two statistics I present in Table 2 of the main text to analyze the models' predictive validity, I also created separation plots for Models 1-3. Separation plots allow the researcher "to evaluate model fit based upon the models' ability to consistently match high-probability predictions to actual occurrences of the event of interest, and low-probability predictions to nonoccurrences of the event of interest" (Greenhill et al. 2011: 990). In more detail, these plots rearrange the data so that predicted values are sorted in ascending order (i.e., increase from left to right). In turn, actual instances of the outcome (in my case, ratification) and non-events are compared with these predicted values to assess whether and how they correspond. In the words of Greenhill et al. (2011: 994): “[t]he key idea is that the model's fit (or predictive power) can now be evaluated by simply gauging the extent to which the actual instances of the event are concentrated at the bottom end of the table (right-hand side of the plot), and the nonevents at the top end of the table (left-hand side of the plot). A model with no predictive power - i.e., one whose outcomes can be approximated by a random coin toss - would generate an even distribution of 0 s and $1 \mathrm{~s}$ along the column on the right-hand side." 
In other words, for a model with reasonable predictive power, we would observe a "clustering" of most events (darker areas or bars) on the right-hand side of the plot. Figure A2 summarizes my findings. As this graph demonstrates, the main text's models fit the data reasonably well: most "events" are clustered on the right-hand side of the figure, although a few outliers (i.e., events on the left-hand side in each plot) do exist. This is likely to be driven by the underlying data-generating process: ratification usually is a rare event.

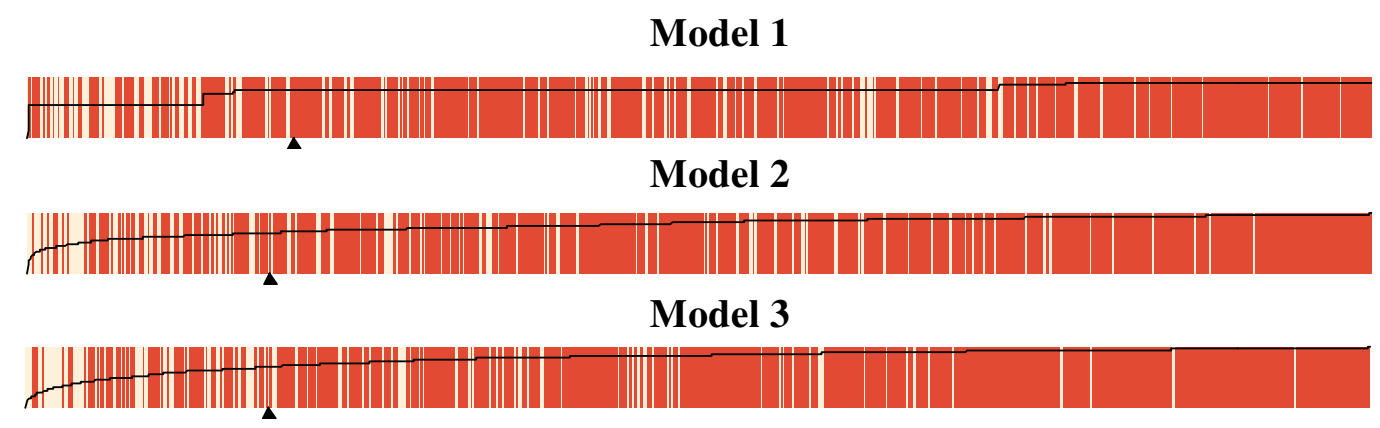

Figure A2. Separation Plots

Note: The graph depicts separation plots for the article's main models (Model 1: top plot; Model 2: middle plot; Model 3: bottom plot). The line in each plot pertains to the predicted values (ascending order from 0 to 1). The marker (triangle) at each plot's horizontal axis stands for the expected number of events: 1,780 (Model 1), 1,819 (Model 2), and 1,819 (Model 3).

\section{International Agreements in Data Set}

\section{Name of International Agreement}

\footnotetext{
Anti-Corruption Convention

Arrest of Ships Convention

Assignment of Receivables Convention

Biodiversity Convention

Cartagena Biosafety Protocol

CCW Protocol II (Mines. Booby-Traps)

Chemical Weapons Convention

Children in Armed Conflict Protocol

Climate Change Convention

Compr. Nuclear-Test-Ban Treaty

Electr. Communications Convention

FAO Plant Genetic Resources
} 
Financing of Terrorism Convention

Hague PIL: Convention of International Protection of Adults

Hague PIL: Convention on Choice of Court Agreements

Hague PIL: Convention on Parental Responsibility

Hague PIL: Convention on Protection of Children \& Adoption

ICAO: Convention on the Marking of Plastic Explosives for the Purpose of

Detection

IMO Convention on Oil Pollution

Int. Cocoa Agreement

Int. Coffee Agreement

Int. Sugar Agreement

Int. Tropical Timber Agreement

Kyoto Protocol

Maritime Liens \& Mortgages Convention

Migrant Workers Convention

Migrants Smuggling Protocol

Nuclear Terrorism Convention

Ottawa (Mine Ban) Convention

Person Trafficking Protocol

Prostitution of Children Protocol

Revised Kyoto Convention

Rome Statute Crime Convention

Rotterdam Convention

Stand-by Letters of Credit Convention

Stockholm Convention (POP)

Straddling Fish Stocks Agreement (Law of the Sea)

Terrorist Bombings Convention

Trans Terminals Liability Convention

Transnational Org Crime Convention

UN Desertification Convention

UN Firearms Protocol

UN International Watercourse Convention

UN Jurisdict. Immunities Conv

UN Personnel Safety Convention

UNIDROIT Convention and Protocol on International Interests in Mobile

Equipment

UNIDROIT Convention Cultural Objects

WIPO Copyright Treaty

WIPO Patent Law Treaty

WIPO Performances \& Phonograms Treaty

WIPO Trademark Law Treaty

WTO GATT

WTO Umbrella Agreement 


\section{References for the Supplementary Materials}

Beck, Nathaniel. 2001. Time-Series-Cross-Section Data: What Have We Learned in the Past Few Years? Annual Review of Political Science 4(1): 271-293.

Beck, Neil, Jonathan Katz, and Richard Tucker. 1998. Taking Time Seriously: Time-Series Cross-Section Analysis with a Binary Dependent Variable. American Journal of Political Science 42(4): 1260-1288.

Bernauer, Thomas, Tobias Böhmelt, and Vally Koubi. 2013. Is There a Democracy-Civil Society Paradox in Global Environmental Governance? Global Environmental Politics 13(1): 88-107.

Box-Steffensmeier, Janet, and Bradford Jones. 2004. Event History Modeling: A Guide for Social Scientists. Cambridge: Cambridge University Press.

Box-Steffensmeier, Janet, Dan Reiter, and Christopher Zorn. 2003. Nonproportional Hazards and Event History Analysis in International Relations. Journal of Conflict Resolution 47(1): 33-53.

Box-Steffensmeier, Janet, and Christopher Zorn. 2001. Duration Models and Proportional Hazards in Political Science. American Journal of Political Science 45(2): 972-988.

Brambor, Thomas, William Clark, and Matt Golder. 2006. Understanding Interaction Models: Improving Empirical Analyses. Political Analysis 14(1): 63-82.

Bueno de Mesquita, Bruce, Alastair Smith, Randolph Siverson, and James D. Morrow. 2003. The Logic of Political Survival. Cambridge, MA: MIT Press.

Croco, Sarah. 2011. The Decider's Dilemma: Leader Culpability, War Outcomes, and Domestic Punishment. American Political Science Review 105(3): 457-477.

Dunlap, Riley, Chenyang Xiao, and Aaron McCright. 2001. Politics and Environment in America: Partisan and Ideological Cleavages in Public Support for Environmentalism. Environmental Politics 10(4): 23-48. 
Elsig, Manfred, Karolina Milewicz, and Nikolas Stürchler. 2011. Who Is In Love with Multilateralism? Treaty Commitment in the Post-Cold War Era. European Union Politics 12(4): 529-550.

Fredriksson, Per, and Noel Gaston. 2000. Ratification of the 1992 Climate Change Convention: What Determines Legislative Delay? Public Choice 104(3/4): 345-368.

Greenhill, Brian, Michael Ward, and Audrey Sacks. 2011. The Separation Plot: A New Visual Method for Evaluating the Fit of Binary Models. American Journal of Political Science 55(4): 990-1002.

Guan, Weihua, et al. 2003. From the Help Desk: Bootstrapped Standard Errors. Stata Journal 3(1): 71-80.

King, Gary and Langche Zeng. 2001. Explaining Rare Events in International Relations. International Organization 55(3): 693-715.

Mattes, Michaela, Brett Ashley Leeds, and Royce Carroll. 2015. Leadership Turnover and Foreign Policy Change: Societal Interests, Domestic Institutions, and Voting in the United Nations. International Studies Quarterly 59(2): 280-290.

Milewicz, Karolina, and Manfred Elsig. 2014. The Hidden World of Multilateralism: Treaty Commitments of Newly Democratized States in Europe. International Studies Quarterly 58(2): 322-335.

Neumayer, Eric. 2003. Are Left-Wing Party Strength and Corporatism Good for the Environment? Evidence from Panel Analysis of Air Pollution in OECD Countries. Ecological Economics 45(2): 203-220.

Neumayer, Eric. 2004. The Environment, Left-Wing Political Orientation, and Ecological Economics. Ecological Economics 51(3-4): 167-175. 
Plümper, Thomas, and Vera E. Troeger. 2007. Efficient Estimation of Time-Invariant and Rarely Changing Variables in Finite Sample Panel Analyses with Unit Fixed Effects. Political Analysis 15(2): 124-139.

Schneider, Christina J., and Johannes Urpelainen. 2013. Distributional Conflict between Powerful States and International Treaty Ratification. International Studies Quarterly 57(1): $13-27$. 